\title{
Using Software for Digitizing and Visualizing Well Logging Data for Modeling in Geology
}

\author{
Yuriy Vikhot \\ Faculty of Geology \\ Ivan Franko National University of Lviv \\ Lviv, Ukraine \\ yuvik@ukr.net
}

\begin{abstract}
Well logging is important for a detailed restored of the features of the geological structure of the investigation area drilled by wells. Logs are divided into geological and geophysical. Well logging identifies the lithology, location of fractures on depth, and record the important physical parameters (temperature, pressure, gamma, neutron, resistivity etc.). Specialized software for digitizing and visualizing well data is necessary for qualitative well logging interpretation. Interpretation of well data are needed for geological modeling, construct 2D profile and 3D model, oil and gas industry, etc.
\end{abstract}

Index Terms-well logging data, well log, digitizing, visualizing, modelling in geology, oil and gas industry, NeuraLog. Ukrainian Carpathians, Ukrainian Carpathian Foredeep.

\section{INTRODUCTION}

Now, in the period of development of geoinformation technologies, in the world there is a progressive introduction of GIS into the geological and geophysical field. The geophysics of global international companies specializing in oil and gas exploration cannot do without the extensive application of special software for digitizing and visualizing primary geophysical well data obtained, for example, by various types of logging.

Geophysical well logging is important key technology in petroleum, geotechnical, mineral, groundwater and geothermal industries. Logging in petroleum is done to determine porosity and hydrocarbon saturation, the location of fractures and recording of physical parameters. Well logging is done during all phases of drilling, production.

Global transnational geophysical petroleum and service companies or corporations (for example, Shlumberger Limited, Chevron Corporation, BP Public Limited Company, Royal Dutch Shell Corporation, Shell Oil Company, etc.) use digital well data at all stages of geophysical and geological research using modern equipment, at times increases the productivity of digital logging data entry. The achievement of international oil companies in field geophysics is the use of their own specially developed software for digitization and creation of bases of primary geophysical well data during geophysical survey of wells.

Although often such corporations use the services of other leading service companies (for example, Interactive Network
Technologies Inc., Neuralog Inc., Landmark Graphics, GeoQues, etc.). For example, HTML5Viewer software, developed by the service company INT Inc., operating under the operating systems Window, Linux, MacOS.

One of the advantages of HTML5Viewer is that it allows to display and analyze 2D and 3D well drilling data, log data, seismic data created in LAS formats (* .las, Log ASCII Standard), DLIS $*$.dlis, Digital Log Interchange Standard File), SEG-D, SEG-Y (* .sgy, * .segy), etc. in an accessible Web browser on desktops and mobile devices using an interactive browser. View files with their logs, display trajectories of vertical and inclined wells in 3D, seismic profiles, etc. Having access to the data server via the Internet, you can anywhere and at any time, which is useful for the oil corporations or geophysical organizations.

\section{SOFTWARE FOR DIGITAZING AND VIZUALIZING WELL LOGGIN}

Today, there is many software for digitizing logs used by companies in the world. The main disadvantage of them is that most of them have a commercial purpose. However, some of them provide short-term licenses for familiarization, and some developers give the opportunity to purchase software at a much lower price for academic purposes. Almost all software run under the most common operating systems Windows XP, Vista, Windows 7, Windows 8, Windows 8.1, Windows 10, Linux, Mac OS X and others.

The leader in the development of software and devices for the digitization, processing, editing, visualizing and transformation of well data for the oil and gas industry is the company Neuralog Inc. [1]. Its software package NeuraLog is one of the best software for carrying out logging digitization from paper originals contains logging data. The software runs under the operating systems Windows 2000, Windows XP, Vista, Windows 7, Windows 8.

The software module turns the scanned paper logs into usable digital well data (in *.las) file formats in other geological software packages. NeuraLog allows automatic digitization, quality improvement, editing and verification of logging curves. In addition, in this application, you can enter the necessary information about the log: information on the drilling area, well data (coordinates, depth, scale), date of 
measurements, start and completion of drilling, type and number of the radioactive source, probe type, operator data and other.

Digitized and visualized data on one or several wells saved in LAS format (*.las) can be presented in other software modules, such as NeuraMap, NeuraSection, NeuraView, NeuraDesktop. For example, NeuraMap works with digital maps and provides automatic creation of digital vector maps with all data from scanned paper originals for analysis, allows for the calculation of volume and reserves by downhole data, etc.

Another NeuraSection software module provides geological interpretation of geophysical data based on the correlation of raster and digital logs digitized in the NeuraLog software, lithological data, and allows the creation and analysis of transverse geological profiles.

Auxiliary applications NeuraView, NeuraDesktop allow you to view, scan raster paper maps and logs, print digitized well data, organize, create databases and visualize geological data, and construct sections using an interactive screen. NeuraDesktop provides a view of all project data in one application. In addition, Neuralog Inc. offers equipment for scanning logs with special large-format or portable scanners (NeuraScanner) and for printing with special laser and inkjet printers (WellLogPrinter). The main significant disadvantage of all software modules of Neuralog Inc. is that they are intended only for commercial use, although you can get a free license, but for a short time.

Another software LogView ++ , the developer of which is Sugiyanto Suwono (Indonesia), is free and can work under the operating systems Windows XP SP3, 7, 8, 8.1, 10 [2]. However, LogView ++ is not much functionality, as the software modules of Neuralog Inc.

The software LogView ++ works with ready-made borehole data and supports the universal *.las format. With the help of tools and options, LogView ++ can be edited, add new data for wells, perform correlation between wells and build a geological cross-section and a lithologic column for different geophysical well data.

The WellCAD 5.1 software package developed by Advanced Logic Technology [3] includes several software modules: WellCAD, LithCAD, ToadCAD and HeadCAD. WellCAD 5.1 is intended for commercial use only. WellCAD software module supports and allows editing, processing, analyzing and visualizing well data in the formats (*.las, *.dlis), and also supports vector and scanned raster data formats (*.csv, *.bmp, *.tif).

Another software package of the American company Golden Software, LLC is the Strater 5 [4]. Strater 5 allows you to compare the curves of different types of logging and on the basis of the information obtained make a transverse geological section and a lithological column and make corrections based on petrophysical studies.

Software LogPlot 8 , the developer is the company RockWare, runs under the operating systems Windows 7, Windows 8, Windows 10 [5]. LogPlot 8 is designed for graphical display and visualization of geophysical well data, including curves of various logging types, and allows storing and opening files in various data formats, including *.las format. The graphic processing of the well data in this software module can be represented in the powerful RockWorks software [6], which has more functionality and allows to compare the geophysical data obtained from several wells.

RockWorks 17 software works with various types of data, such as maps, boreholes, sections, diagrams, etc. RockWorks 17 allows you to represent the borehole data in the form of 2-D and 3-D models. In addition, this software allows you to put the data on the map using the Google Earth application. Software LogPlot 8 and RockWorks 17 commercial use, but also provided for the academic license for the smaller fee.

Software GeoScene3D is 3D geological modelling software for visualizing geoscience data. GeoScene3D is standard software for geoscience data in Denmark. The developers are Danish Geological Survey (GEUS), the Danish Nature Agency and major Danish engineering companies. GeoScene3D support a variety of data types and have import for easy to visualize well data. Software GeoScene3D are used geological and geophysical well data, borehole logs, seismic data, digital terrain models, map data, etc. GeoScene3D is based on three fundamental views on model and data, all integrated and interlinked: Cross Sections, GIS maps, 3D Scenes.

In addition, there are many software for automatic digitization of seismic records obtained with the help of seismographs. Among them, the most common are SeisDig [7, 8], Teseo2 [9]. For example, Teseo2, a software package developed within the framework of the seismic project of the Institute of Geophysics and Volcanology (Italy), is free and works under many operating systems (Linux, Windows, MacOS X, Solaris, etc.).

\section{THE SCIENTIFIC NOVELTY}

Almost all geophysical data of well logging from oil and gas wells from the territory of the Ukrainian Carpathians and Ukrainian Carpathian foredeep are in the paper form of the logs, some of which are even poorly preserved (Figure 1).

A digital version of well $\log$ data in special formats (for example, LAS File Format, DLIS) could only be allowed by a few foreign companies or those that already had the appropriate software.

Few foreign companies or those that already had the appropriate software could using the digital version of well log data in special formats (for example, LAS File Format, DLIS).

Many digital well log data remain inaccessible for Ukrainian geophysical and geological company used for studying the geological section, calculate oil and gas reserves and control the development of oil and gas fields.

Visualizing the results and analyzing the geophysical data of field geophysics - geophysical logging data, borehole seismic data - cannot be performed high-quality on a high scientific level without the ability to use modern geophysical software and without using certain software modules. 

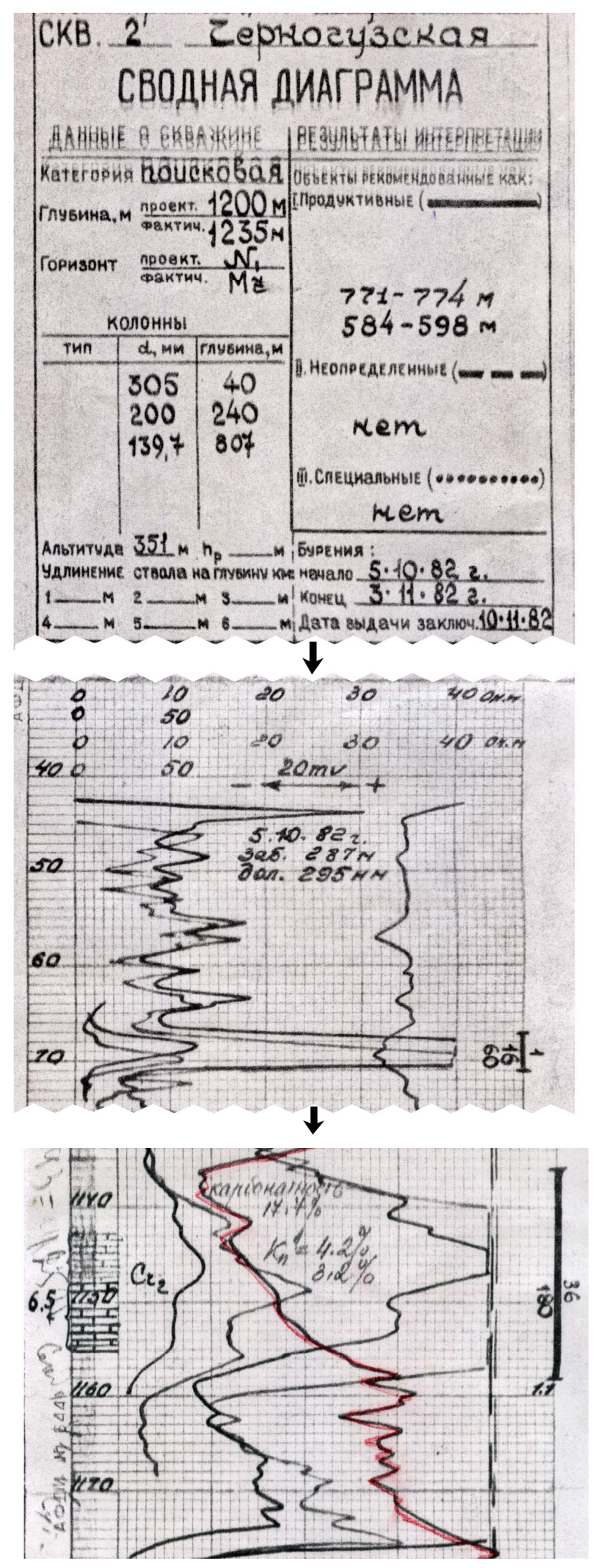

\section{REFERENCES}

[1] NeuraLog. www.neuralog.com

[2] LogView++. https://firagiel.com/web/technical-software/logview/

[3] WellCAD 5.1. https://www.alt.lu/software.htm

[4] Strater 5. http://www.goldensoftware.com/products/strater

[5] LogPlot 8. https://www.rockware.com/product/overview.php?id=176

[6] RockWorks 17. https://www.rockware.com/

[7] SeisDig. http://iodlabs.ucsd.edu/peter/seismology/SeisDig.html

[8] Bromirski, P.D. Chuang S. SeisDig : Software to Digitize Analog Seismogram Images, User's Manual, Scripps Institution of Oceanography Technical Report. - 2003. - 28 pp. http://escholarship.org/uc/item/76b2m74m.

[9] Teseo2. http://teseo.rm.ingv.it/

[10] GeoScene3D. https://www.geoscene3d.com/software/geoscene3d

Figure 1. The scanned fragment of the paper form of well loging from the Chornoguz gas area (2-Chornoguz well, Chernivtsi region, Ukrainian Carpathian foredeep) 